\section{Nomenclature Madness}

The way the Commission on Biochemical Nomenclature of the International Union of Pure and Applied Chemistry-International Union of Biochemistry would like biochemists to denote the peptide Ser-Ile-LeuLeu-Tyr is by the word SILL Y. The commission decided that the familiar and sensible threeletter symbols which are used to denote amino-acids occupy too much space, especially when they are used for comparing long sequences in tables, lists or figures. The commission was apparently also worried that, in printing, alignment of amino-acid sequences which are being compared is not always perfectly maintained because of variations in the size of letters and amount of production. And, on top of all this, three-letter symbols are not as suitable as single-letter symbols for computer storage of large amino-acid sequences.

This is why the commission set up a subcommission to devise a one-lettor notation system for the twenty amino-acids. By some oversight, when the aminoacids were originally named they were not given twenty different initial letters. As a result, apart from cysteine, histidine, isoleucine, methionine, serine and valine, where there is no ambiguity, the subcommission has had arbitrarily to decide which amino-acids to represent by initial letters and which by some other. The accompanying table shows the result.

$\begin{array}{ll}\text { A } & \text { Ala } \\ \text { B } & \text { Asx* } \\ \text { C } & \text { Cys } \\ \text { D } & \text { Asp } \\ \text { E } & \text { Glu } \\ \text { F } & \text { Phe } \\ \text { G } & \text { Gly } \\ \text { H } & \text { His } \\ \text { I } & \text { Ile } \\ \text { K } & \text { Lys } \\ \text { L } & \text { Leu } \\ \text { M } & \text { Met }\end{array}$

$\begin{array}{ll}\text { N } & \text { Asn } \\ \text { P } & \text { Pro } \\ \text { Q } & \text { Gln } \\ \text { R } & \text { Arg } \\ \text { S } & \text { Ser } \\ \text { T } & \text { Thr } \\ \text { V } & \text { Val } \\ \text { W } & \text { Trp } \\ \text { X } & \text { Unknown or "other" } \\ \text { Y } & \text { Tyr } \\ \text { Z } & \text { Glx* }\end{array}$

$\mathrm{B} \simeq \mathrm{Asx} *$ for aspartic acid or asparagine when undetermined. $\mathrm{Z} \simeq \mathrm{Glx}^{*}$ for glutamic acid or glutamine wben undetermined.

Perhaps realizing that there is no hope of this nomenclature being widely adopted, the subcommission says its nomenclature should be used in comparisons of long sequences. It should not be used to designate details of short peptides, in reporting experiments on protein synthesis or in papers where the single letter system is used for nucleoside sequences or codons. But with all these exceptions is the new system useful enough to warrant adoption? The subcommission seems to have forgotten that the only justification for abbreviations, like any shorthand, is speed and convenience. Its single-letter notations are hardly likely to have either. Is everyone supposed to learn the abbreviations or carry about little lists to translate what otherwise will be meaningless sequences? What will happen when in the same report it is essential to give complete sequences and details about protein synthesis? The confusion if both systems are used simul- taneously will be complete. But an even more telling objection to a single-letter system will come in the future when it is possible to compare amino-acid sequences of proteins with the base sequences of the $m \mathrm{RNA}$ and DNA that specifies the protein. How will it be possible to maintain perfect alignment between a sequence of triplet codons and single-letter abbreviations for the amino-acids they specify? If the present three-letter system can be troublesome, the new system will be hopelessly so. It is an unnecessary and inconvenient complication which will no doubt be ignored.

\section{Australia's Poisonous Plants}

THe toxic principle ricin in castor oil is removed from the seeds of the castor oil plant (Ricinus communis L.) during the preparation of medicinal oil, but remains in industrial castor oil. It is extremely toxic. Because the plant is a common weed in many parts of Australia, it is included in Plants Harmful to Man in Australia, published by the Botanic Garden in Adelaide (Miscellaneous Publications No. 1, \$1 Australian).

The booklet is an extended form of a brochure produced in 1966 for the third convention of the Australian College of General Practitioners. The plants dealt with in the booklet are those which cause injury as a result of ingestion or skin contact. The list includes fungi, although there scem to be few records of specific poisoning by fungi in Australia, possibly because of Anglo-Saxon eating habits.

Identification of fungi is a problem. Apparently colour, odour, taste, discoloration after peeling the cap, blackening of silver articles, coagulation of milk, and eating by animals are dangerous criteria originating in folklore. For positive identification a specialist mycologist is required. The booklet does, however, discuss the clinical symptoms of poisoning by fungi, chiefly with reference to the genus Amanita, of which a generalized drawing is provided. A. phalloides, the death cap fungus, which probably accounts for 90 per cent of all deaths from mushroom poisoning, is believed to have come to the Canberra area with imported seedlings.

The flowering plants are all described briefly in the booklet, together with a statement of the symptoms of poisoning and available treatment and antidotes. Most toxic substances in plants are alkaloids or glycosides, and, as this booklet says, the principal hazard is not so much in the plants themselves as in our ignorance of them.

\section{Chromosome Structure}

\section{from our Cell Biology Correspondent}

IT is reasonable to believe that chromosomes contain an ordered and reproducible structure. At the level of resolution of the light microscope they have a characteristic form which allows the recognition of individual chromosomes, and it is difficult to imagine how DNA molecules, some of them metres in length, can be 